\title{
REVERSIBLE CARDIOMYOPATHY IN CUSHING SYNDROME-A RARE PRESENTATION
}

\author{
D. Malleshwar Rao
}

\begin{abstract}
:
Cushing syndrome (CS) is the result of extended exposure to excessive glucocorticoids from endogenous or exogenous sources. Cushing's syndrome (CS) is associated with reduced life quality and increased mortality, mostly due to cardiovascular disease. We report the case of a 26-year-old female patient who presented with heart failure who was found to have Cushing syndrome and recovered after supportive treatment.
\end{abstract}

\section{INTRODUCTION}

Cushing syndrome(CS) is caused by prolonged exposure to elevated levels of either endogenous glucocorticoids or exogenous glucocorticoids. Cardiovascular disease is the major cause of morbidity and mortality in Cushing's syndrome, and excess risk remains even in effectively treated patients. The cardiovascular consequences of cortisol excess are protean and include elevation of blood pressure, truncal obesity, hyperinsulinemia, hyperglycemia, insulin resistance, and dyslipidemia. Cardiovascular complications, such as premature atherosclerosis, coronary artery disease, and stroke, in patients with CS cause a mortality rate higher than that observed in a normal population. CS associated with dilated cardiomyopathy(DCM) without $\mathrm{LVH}$ is rare. Here we are presenting a case of CS with DCM which on follow up showed improvement of LV function.

Article received on 8July 2016, published on 30 July 2016. D. Malleshwar Rao ${ }^{1}$,

${ }^{1}$ Senior Resident, Department of Cardiology, NIMS, India Corresponding author: D Malleshwar Rao,

Email: ramakrishnaji83@gmail.com.

\section{CASE REPORT}

A 26 -years-old woman(gravida 2, Para 2) presented to the emergency department (ED) with a 1-week history of progressive dyspnea, orthopnea, and swelling of the lower limbs. She was in her usual state of health until 1week ago, when she developed progressive and worsening dyspnea. Dyspnea was worse during exertion and was associated with decreased exercise tolerance. Two days later, patient had experienced painless bilateral lower extremity swelling that reached her mid leg, with no erythema or warmth. Patient reported paroxysmal nocturnal dyspnea since last 3 days.

She did not have any palpitations or dizziness, and she had not experienced any syncope. She denied having subjective fever, abdominal pain, or vomiting. She had not had any wheeze or chest pain. The patient's medical history was remarkable only for delivery that occurred 8 months ago. At that time, she underwent caesarean section; she has been doing well since then. The patient did not have any chronic medical conditions and does not take any regular medications. She was not a smoker or alcoholic and had no family history of cardiomyopathy.

Physical examination revealed a breathless woman with rounded facies, truncal obesity, and abdominal striae. At time of admission her blood pressure was 180/90 $\mathrm{mm} \mathrm{Hg}$, and pulse was 110 beats per minute and regular. She was a febrile. No lymphadenopathy, cyanosis, or clubbing was seen. Her respiratory rates were high with mildly increased work of breathing and oxygen saturation is low (at 24 breaths/min and $88 \%$ while breathing room air, respectively) at admission. Her heart sounds were normal, without any murmurs or gallops. She had a soft and non-tender abdomen. Her weight was $64 \mathrm{~kg}$ (body mass index, $28.5 \mathrm{~kg} / \mathrm{m}^{2}$ ). There 
were signs of decompensated biventricular heart failure, which included rales in the lower lung fields bilaterally, raised jugular venous pressure, and peripheral edema. Patient had moon face and abdominal stria. She had no abnormalities in visual acuity or visual field.

Arterial blood gas sample obtained while the patient was breathing room air showed a $\mathrm{pH}$ of 7.449 , a partial pressure of carbon dioxide of $31.6 \mathrm{~mm} \mathrm{Hg}$, a partial pressure of oxygen of $63.9 \mathrm{~mm} \mathrm{Hg}$, and an oxygen saturation of $93.2 \%$ on room air. Electrocardiography showed sinus tachycardia with heart rate of 110 per minute, Left axis deviation, poor $\mathrm{R}$ wave progression, and Low amplitude $\mathrm{T}$ waves with QT interval of 400 msec ( $\left.\mathrm{QT}_{\mathrm{c}}-522 \mathrm{msec}\right)$. Transthoracic echocardiography revealed a slightly dilated left ventricle, normal left ventricle myocardial thickness, decreased left ventricular ejection fraction (LVEF) of 31.6\%, mild mitral regurgitation, and mild tricuspid regurgitation with mild pulmonary arterial hypertension (RVSP $=46 \mathrm{~mm}$ $\mathrm{Hg}$ ) .Patient had good right ventricular function. Chest radiography revealed pulmonary edema and Cardiomegaly. Ultrasonography findings in the abdomen and chest were mild bilateral pleural effusion with no free fluid in the abdomen with normal sized liver, spleen, and kidney. NT pro BNP of the patient was very high.

Fig 1 :Transthoracic Echocardiography at the time of admission showing global hypokinesia with severe left ventricularsystolic dysfunction $(\mathrm{EF}=31.6 \%)$

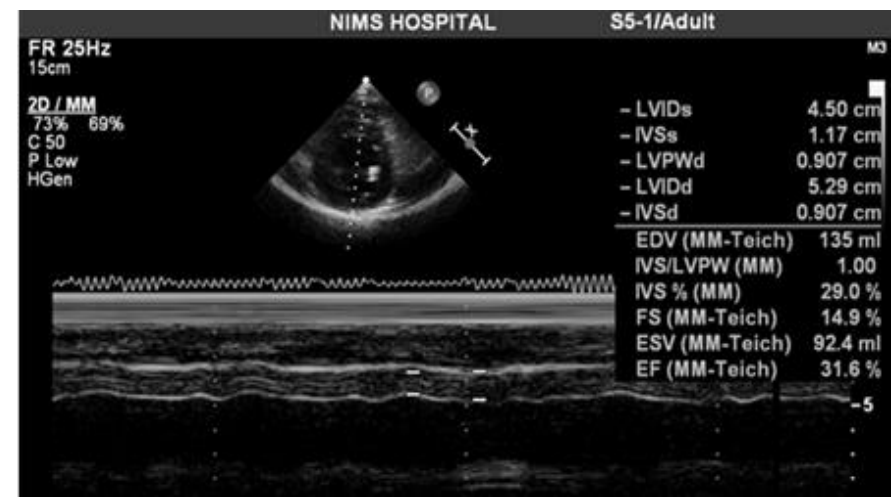

Relevant serum biochemistry findings on presentation and at time of discharge are shown in Table 1 and 2. She was found to have hyperglycemia. Complete blood picture revealed normocytic microcytic anaemia with normal WBC counts. Patient was evaluated for anaemia and found to have iron deficiency anaemia. Patient had hypokalaemia before giving diuretics that persisted for 4 days despite oral supplementation. Hence hypokalaemia was corrected with intravenous KCL solution at a rate according to standard guidelines. Presence of hypertension with persistent hypokalaemia along with moon face directed investigations towards Cushing syndrome. Patient denied exogenous intake of oral, parenteral, inhaled, or topical corticosteroids.

Fig 2: Transthoracic echocardiography during follow up showing normalised left ventricular systolic function.

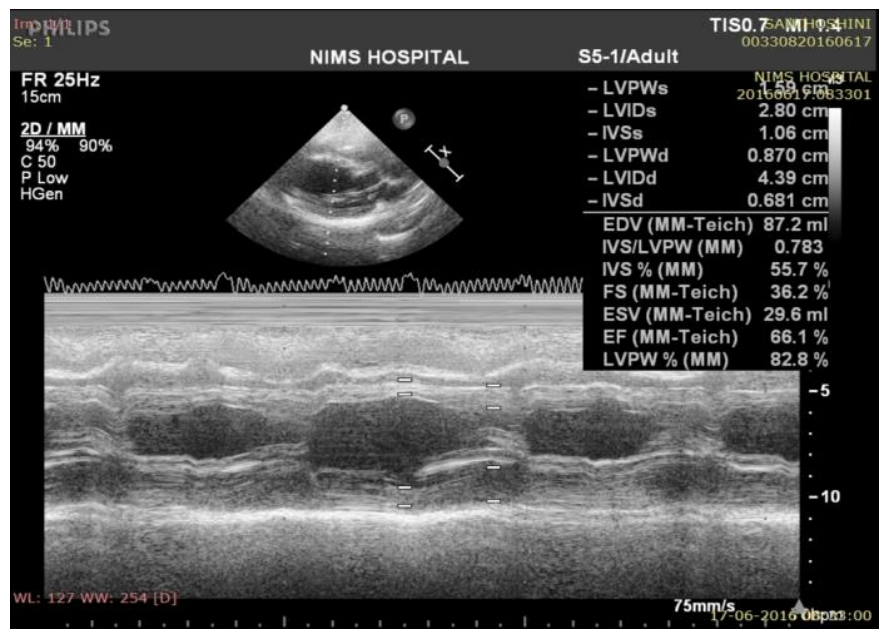

Urine free cortisol (UFC)over 24 hours was very high and Low-dose (1 $\mathrm{mg})$ overnight dexamethasone suppression test (DST) failed to suppress serum cortisol below $1.8 \mathrm{ug} / \mathrm{dl}$ both of which confirms Cushing syndrome. Serum ACTH levels are $40 \mathrm{pg} / \mathrm{ml}$. CECT abdomen showed normal sized adrenal glands with no evidence of any mass(Picture 3). Patient has been given diuretics, intravenous nitroglycerine titrated according to BP and oxygen inhalation. Patient had shown significant improvement symptomatically. Transthoracic echocardiography after one month showed marked improvement in ejection fraction(Picture 2).Since ACTH levels were low and patient improved without any specific treatment for Cushing syndrome, drug induced Cushing is more likely. 
Fig 3: Contrast Enhanced CT abdomen showing normal sized adrenal glands (arrows) on both sides with no evidence of mass.

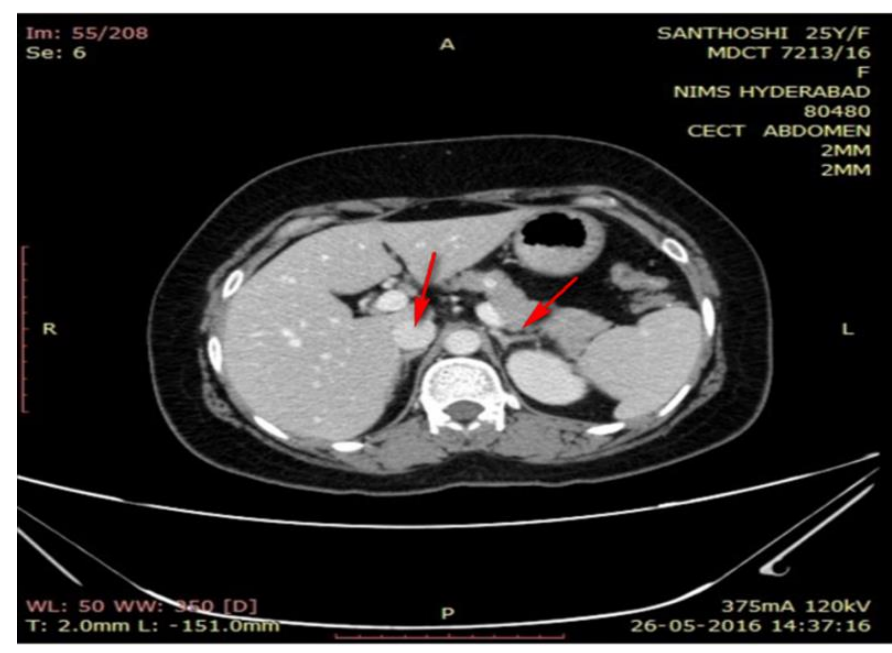

Table 1: ABG

\begin{tabular}{|l|l|l|}
\hline $\begin{array}{l}\text { Lab } \\
\text { parameters }\end{array}$ & Normal range & Patient's value \\
\hline $\mathrm{pH}$ & $7.35-7.45$ & 7.449 \\
\hline $\mathrm{pCO}_{2}$ & $35-48 \mathrm{~mm} / \mathrm{Hg}$ & $31.9 \mathrm{~mm} / \mathrm{Hg}$ \\
\hline $\mathrm{p}_{2}$ & $83-108 \mathrm{~mm} / \mathrm{Hg}$ & $63.9 \mathrm{~mm} / \mathrm{Hg}$ \\
\hline $\mathrm{HCO}_{3}$ & $21-28 \mathrm{mmol} / \mathrm{L}$ & $21.5 \mathrm{mmol} / \mathrm{L}$ \\
\hline Anion gap & $7-16 \mathrm{mmol} / \mathrm{L}$ & $15 \mathrm{mmol} / \mathrm{L}$ \\
\hline
\end{tabular}

\section{DISCUSSION}

Reversible dilated cardiomyopathy has been associated rarely with Cushing syndrome and very few cases have been reported so far. Although skeletal myopathy is known to occur in Cushing syndrome, our knowledge on cardiomyopathy in Cushing syndrome is limited.

Several previous studies have studied cardiac changes in patients with Cushing syndrome. These studies revealed changes in the left ventricular structural characteristics, in particular asymmetric wall thickening, suggesting cardiac remodeling. These changes correlated significantly with duration of disease but not with blood pressure and urinary cortisol levels. These studies have shown that cardiac remodeling occurs in CS independent of hypertension. Despite findings of
Table 2: Biochemical Parameters

\begin{tabular}{|c|c|c|c|}
\hline Lab parameters & $\begin{array}{l}\text { Normal } \\
\text { range }\end{array}$ & $\begin{array}{l}\text { At time of } \\
\text { presentation }\end{array}$ & $\begin{array}{l}\text { At time of } \\
\text { discharge }\end{array}$ \\
\hline $\begin{array}{l}\text { Haemoglobin } \\
(\mathrm{gm} / \mathrm{dL})\end{array}$ & $12-16$ & 8.1 & 11.4 \\
\hline $\begin{array}{l}\text { Total leucocyte } \\
\text { count (cells } / \mathrm{mm}^{3} \text { ) }\end{array}$ & $\begin{array}{l}4000- \\
11000\end{array}$ & 8600 & 7100 \\
\hline Differential count & & $\begin{array}{l}\text { P62,L30,M7, } \\
\text { E1 }\end{array}$ & $\begin{array}{l}\text { P56, L25, } \\
\text { M7, E3 }\end{array}$ \\
\hline $\begin{array}{l}\text { Platelet count } \\
\left(\text { lakhs } / \mathrm{mm}^{3}\right)\end{array}$ & $\begin{array}{l}1.50- \\
3.50\end{array}$ & 2.8 & 2.2 \\
\hline $\begin{array}{l}\text { Blood urea } \\
(\mathrm{mg} / \mathrm{dL})\end{array}$ & $15-40$ & 37 & 25 \\
\hline $\begin{array}{l}\text { Serum creatinine } \\
(\mathrm{mg} / \mathrm{dL})\end{array}$ & $0.9-1.4$ & 1.1 & 0.7 \\
\hline $\begin{array}{l}\text { Serum sodium } \\
(\mathrm{mmol} / \mathrm{L})\end{array}$ & $135-145$ & 120 & 134 \\
\hline $\begin{array}{l}\text { Serum potassium } \\
(\mathrm{mmol} / \mathrm{L})\end{array}$ & $3.5-5.0$ & 2 & 4.8 \\
\hline SGOT $(\mathrm{u} / \mathrm{L})$ & $6-38$ & 10 & 15 \\
\hline SGPT $(\mathrm{u} / \mathrm{L})$ & $5-56$ & 10 & 16 \\
\hline $\operatorname{ALP}(\mathrm{u} / \mathrm{L})$ & $42-98$ & 71 & 86 \\
\hline $\begin{array}{l}\text { Total protein } \\
(\mathrm{gm} / \mathrm{dL})\end{array}$ & $6-8.3$ & 5.5 & 5.6 \\
\hline Albumin (gm/dL) & $3.5-5.5$ & 3.2 & 3.4 \\
\hline $\begin{array}{l}\text { Total bilirubin } \\
(\mathrm{mg} / \mathrm{dL})\end{array}$ & $0.3-1.2$ & 0.2 & 0.3 \\
\hline $\mathrm{T} 3(\mathrm{nmol} / \mathrm{L})$ & $1.3-3.1$ & 1.6 & 1.8 \\
\hline T4 (ug/dL) & $5-14$ & 7.4 & 7.2 \\
\hline TSH (uIU/ml) & $0.2-4$ & 6.7 & 6 \\
\hline Urinary VMA & & Negative & \\
\hline $\begin{array}{l}\text { NT proBNP } \\
(\mathrm{pg} / \mathrm{ml})\end{array}$ & $<150$ & 15920 & 2800 \\
\hline
\end{tabular}

cardiac remodeling, dilated cardiomyopathy or decompensated congestive heart failure was reported in very studies. BernaImge Aydoganet al [1]. published similar case in journal of case report in cardiology but patient improved only after transnasal/ transsphenoidal adenomectomy unlike our case where patient improved with supportive treatment. The other case is published by Marazuela $\mathrm{M}$ et al[2] in which cardiac function did not improve despite normalization of cortisol levels. In our case cardiac function improved remarkably after supportive treatment alone. The likely explanation is 
transient hypercorisolism due to exogenous intake of some unknown medication.

The pathophysiology of cardiac remodelling and decompensated congestive heart failure involves complex mechanisms including the effects of hypertension and activation of neurohormonal factors $\alpha$-adrenergic and renin-angiotensin-aldosterone systems. The saturation of 11-beta-hydroxysteroid dehydrogenase type 2 enzyme (11 $\beta-H S D 2)$ resulting in mineralocorticoid receptor activation by cortisol has also been suggested as a possible reason for cardiomyopathy [6].

In conclusion, dilated cardiomyopathy is a rare feature of Cushing syndrome. Cardiomyopathy has been reversible in majority of these cases after successful treatment of Cushing syndrome. The mechanism in the development of dilated cardiomyopathy associated with Cushing syndrome has not been defined precisely. Present findings suggest that excess cortisol is contributory to cardiac remodelling and dilated cardiomyopathy.

\section{REFERENCES}

1. Bernaİmge Aydoğan ${ }_{\llcorner}$Demet Menekşe Gerede, Asena Gokçay Canpolat, and Murat Faik Erdogan, Cushing's Disease Presented by Reversible Dilated Cardiomyopathy Case Reports in Cardiology Volume 2015 (2015), Article ID 980897, 3 pages.

2. Marazuela M, Aguilar-Torres R, Benedicto A, et al. Dilated cardiomyopathy as a presenting feature of Cushing's syndrome. Int J Cardiol. 2003;88:331-333.

3. Muiesan ML, Lupia M, Salvetti $M$, et al. Left ventricular structural and functional characteristics in Cushing's syndrome.J Am Coll Cardiol. 2003;41:2275-2279.

4. Fallo F, Budano S, Sonino $\mathrm{N}$, et al. Left ventricular structural characteristics in Cushing's syndrome. J Hum Hypertens. 1994;8:509-513
5. Sugihara N, Shimizu M, Kita Y, et al. Cardiac characteristics and postoperative courses in Cushing's syndrome. Am J Cardiol. 1992; 69:1475-1480.

6. Chu JW, Matthias DF, Belanoff $\mathrm{J}$, et al. Successful long-term treatment of refractory Cushing's disease with high-dose mifepristone (RU 486). J Clin Endocrinol Metab. 2001;86:3568-3573. 